\title{
Transparent and Electrically Conductive Films from Chemically Derived Graphene
}

\author{
Siegfried Eigler \\ DIC Berlin GmbH
}

Germany

\section{Introduction}

The research interest in graphene based materials, especially for high quality graphene emerged due to its unique electronic and mechanical properties. Some exceptional properties are the high charge carrier mobility at room temperature of $2.5 \times 10^{5} \mathrm{~cm}^{2} \mathrm{~V}^{-1} \mathrm{~s}^{-1}$, the thermal conductivity of $5000 \mathrm{WK}^{-1} \mathrm{~m}^{-1}$ and the mechanical stiffness of $1 \mathrm{TPa}$. Moreover, in electronic devices graphene will open up the possibility for a post silicon age. These properties are valid for graphene with a defect-free structure. For large-scale preparation of graphene a processible and versatile precursor called graphene oxide is utilized. (Compton \& Nguyen, 2010).

In this article, a historical overview will be given to elucidate the development of graphene and especially the precursor graphene oxide, its structure in the oxidized and reduced state. Moreover the synthetic methods for graphene preparation will be contemplated. One discipline in graphene research is the preparation of transparent and electrically conductive coatings for the substitution of commonly used transparent conductors as indium tin oxide (ITO), which is currently used for touch screen applications and transparent electrodes. One essential disadvantage of ITO is its brittleness that excludes applications in flexible or wearable electronics.

Furthermore, the performance of such potentially flexible transparent and conductive coatings in dependants of its preparation method will be reviewed using graphene as the reference material. Besides, graphene based transparent coatings will be compared with other suitable transparent coatings.

\section{Historical overview - the development to graphene}

\subsection{The first expansion of graphite}

When did the story begin that resulted in the tremendous interest in the study of the properties and the rich chemistry of graphene? Certainly, it was the group of Geim in Manchester that succeeded to promote the outstanding properties and the research in the field of graphene. Their groundbreaking experiments were honoured 2010 with the nobelprize in physics. So this beginning was in 2004 (Novoselov et al., 2004).

Graphite itself is known for a long time and the name originates from the greek graphein what means to draw or write and was named by A. G. Werner in 1789. At this time the chemical structure of graphite was unknown and it took almost 130 years to clarify that structure. It was K. E. von Schafhaeutl in the $19^{\text {th }}$ century who was a universal scholar and a 
professional in physics, geology, chemistry and music. In 1840 he described an experiment where he observed the exfoliation of graphite. He placed graphite in hot sulphuric acid and added nitric acid that decomposed by the dropwise addition. After the complete decomposition he observed an increased volume of graphite by its expansion or exfoliation to assumedly few layer graphite. Moreover, he repeated that procedure four times until the acid became clear, possibly due to oxidative decomposition of graphite. With the description of these experiments he became a pioneer for modern chemistry on graphite, its intercalated compounds and finally exfoliated graphite (Schafhaeutl, 1840).

\subsection{The synthesis of graphite oxide - from Brodie to Staudenmaier}

A key for the rich chemistry especially on graphene oxide today is the earning of Brodie who discovered the oxidation of graphite to a stable solid product for the first time (Brodie, 1855). Before his discovery of now called graphite oxide, only the impact of sulphuric acid on graphite was studied (Marchand, 1845) and it was known that graphite can be completely oxidized to $\mathrm{CO}_{2}$ by potassium dichromate in sulphuric acid (Rogers \& Rogers, 1850). Brodie used potassium chlorate in nitric acid for the oxidation of graphite and found after repeated treatments a yellow dispersion of transparent particles that he termed graphitic acid. Gottschalk studied the synthesis and properties of that new substance in 1865. He described the stages of oxidation after each oxidation procedure and described the colour change from black over greens to yellow within five repeated oxidation procedures using Brodies method. Moreover, he recognized the darkening of yellow graphite oxide by the exposure of sunlight what can be ascribed to partial reduction of graphite oxide (Gottschalk, 1865).

At the end of the 19th century, Staudenmaier essentially enhanced the preparation procedure to graphite oxide. The advantage was not only a faster procedure but also a much saver one. The problem that caused unpredictable explosions was the formation of accumulative amounts of chlorine dioxide $\left(\mathrm{ClO}_{2}\right)$ that decompose at a temperature of about $60{ }^{\circ} \mathrm{C}$ when a certain concentration is reached. That danger was much lower for the two-step procedure developed by Staidenmaier. In the first step graphite is treated with a mixture of sulphuric and nitric acid and potassium chlorate at ambient conditions. In the second step graphite oxide is yielded by a final oxidation with potassium permanganate (Staudenmaier, 1898). Moreover, it is interesting to note that he described a small-scale lecture experiment for the preparation of graphite oxide (Staudenmaier, 1899). So, the Staudenmaier method rendered possible the preparation of graphite oxide on large scale minimizing the danger of explosions. Further, the preparation time was much lower compared to Brodies method. Instead of several weeks only several days were necessary.

Within the first 50 years of oxidizing graphite to graphite oxide the method could be dramatically enhanced and Staidenmaier pointed out that graphite oxide is not a uniform substance as others thought before, according to elemental analysis. As a consequence no chemical formula can be given for graphite oxide, as others tried before (Staudenmaier, 1899). Nevertheless, the oxygen content of yellow graphite oxide is about $40 \%$ and a simple average formula might be given as $\mathrm{C}_{6 n}(\mathrm{OH})_{3 n}$ without a valid claim.

\subsection{From oxidized graphite to its structure}

In the following years the aim was to identify the structure of graphite. For this purpose the reaction products of oxidized graphite were analyzed. Mellitic acid (benzene-1,2,3,4,5,6- 
hexacarboxylic acid) was identified as one oxidation product of graphite, if the degree of oxidized graphite is higher than graphite oxide but lower than $\mathrm{CO}_{2}$ (Dimroth \& Kerkovius, 1913).

So, it was assumed that $\mathrm{C}_{6}$ is the building block of graphite. Then, in 1917 Debye and Scherrer used x-ray methods to clarify the structure of graphite and diamond and they brought their experiments in the context of chemical oxidation results (Debye \& Scherrer, 1917). Now, the structure of graphite is well-known and common knowledge. The C-C bond length is $1.42 \AA$ and the structure consists of graphene layers that are stacked in an $\mathrm{AB}$ sequence. The sheet distance between two layers is $3.35 \AA$ (Chung, 2002).<smiles>CC1C(C)C(C)C(C)C(C)C1C</smiles>

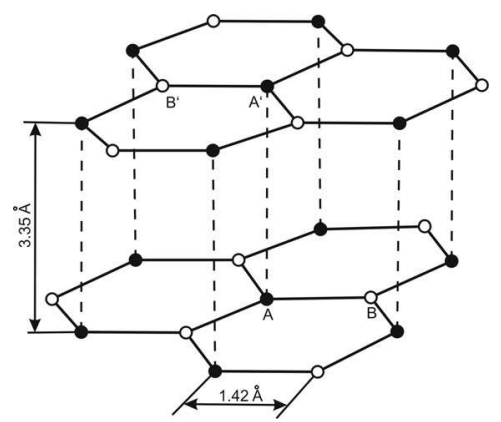

Fig. 1. A) $\mathrm{C}_{6}$-structure motive - a first hint for the structure of graphite as a result of oxidizing graphite (Dimroth \& Kerkovius, 1913); B) reproduced and simplified crystal structure of graphite; C-C bond length is $1.42 \AA$; $\mathrm{AB}$ stacking of graphene sheets (Chung, 2002).

\subsection{Adsorption properties of graphite oxide}

After the structure of graphite was known the development on the chemistry of graphite and graphite oxide was much faster. Researchers determined the chemical properties of graphite oxide in the following decades. E.g. Thiele analysed amongst other things the base exchange with graphite oxide (Thiele, 1937). It was recognized that a dispersion of graphite oxide changes its $\mathrm{pH}$ from neutral to acid upon the addition of ions, as $\mathrm{Na}^{+}, \mathrm{K}^{+}, \mathrm{Ba}^{2+}, \mathrm{NH}_{4}{ }^{+}$ and others accompanied with an increase in the sheet distance of the graphene oxide sheets in graphite oxide. Generalized the data say, that one mol of graphite oxide with the generalized formula $\mathrm{C}_{6}(\mathrm{OH})_{3}$ can adsorb about 1-2 equivalents. A curiosity was the usage of graphite oxide as a model substance for humic acid and lignin because of a similar basic structure, even if graphite oxide exhibits a sheet structure contrary to the others. So, Hamdi generated a tremendous work with the detailed analysis of the adsorption behaviour of graphite oxide. E.g. amino acids, as leucine was determined to be adsorbed to graphite oxide at $\mathrm{pH}=6$, better than valine, alanine or $\mathrm{NH}_{4}{ }^{+}$. Moreover it is interesting to note that he could not find any toxicity of graphite oxide towards the fungi Oospora lactis (Hamdi, 1942).

\subsection{Modern preparation procedures of graphite oxide}

It was in 1957 when Hummers published a patent for the preparation of graphite oxide. There he claimed a simple scalable and innocuous synthetic procedure. He used sulphuric 
acid and sodium nitrate to disperse graphite and potassium permanganate was used as the oxidant. The temperature was kept below $45^{\circ} \mathrm{C}$ and the reaction time was only one hour. This procedure is now called Hummers method. Basically, besides a pre-treatment step of graphite, the procedure did not change any more and the aqueous work-up procedure followed by the addition of hydrogen peroxide to make metal salts removable is easy as well (Hummers, 1957).

Before, it was already known since 1909 that potassium permanganate in sulphuric acid can oxidize graphite at ambient temperature and it was determined that $\mathrm{CO}_{2}$ is formed at a temperature higher than $45^{\circ} \mathrm{C}$ (Charpy, 1909). Nevertheless, it was also described that it is difficult to separate metal salts from the oxidation mixture (Ruess, 1947).

These days, Hummers method or the modified Hummers method is the most commonly used procedure for the synthesis of graphite oxide. Modifications were done by Kovtyukhova et al. using phosphorus pentoxide and potassium peroxydisulfate in sulphuric acid to pre-oxidize graphite to make the subsequent oxidation of graphite according to Hummers method complete (Kovtyukhova et al., 1999). Another method is to use elongated reaction times up to about five days as described by Hirata et al. (Hirata et al., 2004).

\subsection{The chemical structure of graphite oxide}

Even if the structure of graphite oxide was not known for a long time chemical modifications and modern analytical methods elucidated the structure of graphite oxide. According to the latest analytical results the Lerf-Klinowski model describes best the structure of graphite oxide (Lerf et al., 1998; Casabianca et al., 2010).

The structure of graphite-oxide according to the Lerf-Klinowski model can be described as a $\mathrm{CHO}$ macromolecule with aromatic and aliphatic regions. The first ones are untouched and not oxidized. The latter consist mainly of epoxy- and hydroxyl-groups. The amount of these regions depends on the oxidative treatment method. So, on the one hand there are almost flat regions that consist of annulated aromatics, double bonds and epoxy groups. On the other hand there are hydroxyl-groups that cause wrinkles. There are also carboxylic acid groups at the edges of the sheets that can introduce charge in the graphite plane in their deprotonated state. Moreover, this model describes the low reactivity of epoxy-groups that was discussed in former times. Due to the negatively charged sheets and the oxygen functionalities on both sides of the sheets, a reaction with nucleophiles is almost not possible.

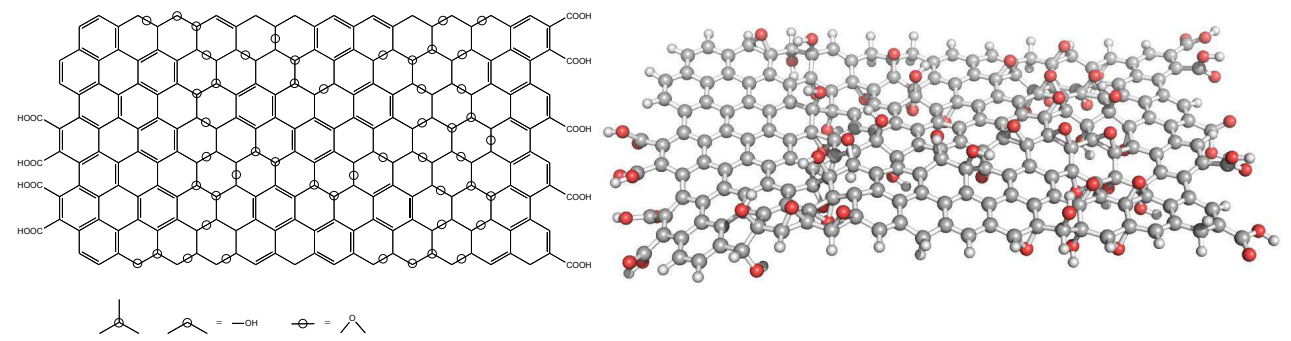

Fig. 2. A) Lerf-Klinowski structure model of graphite oxide; this model is supported by current investigations, reproduced (Lerf et al., 1998). B) Semiempirical AM1-optimized 3DLerf-Klinowski model. 


\subsection{The way to graphene oxide, reduced graphene oxide and graphene}

When one considers the development of oxidized graphite, the question is at what time the transition from graphite oxide to graphene oxide and finally to isolated graphene happened. It was noted that solvent molecules can intercalate graphite oxide which leads to an expansion of the layers. Thereby the sheet distance can increase up to $15 \AA$ for dioxane intercalated graphite oxide. Moreover, water at basic $\mathrm{pH}$ can further increase the sheet distance and it was supposed that graphite oxide exfoliates to single sheets, now called graphene oxide, a two dimensional macromolecule (Ruess, 1947).

The next step to graphene sheets was the thermal decomposition of graphite oxide at a rapid temperature increase to $300{ }^{\circ} \mathrm{C}$. A volume increase by a factor of 500 was described and that material was further cocked to yield a carbon material of more than $99 \%$ purity. It was concluded from electron microscopy that the yielded material consists of few layers only (Ruess \& Vogt, 1948). Such a material is now named reduced graphene oxide.

Then, it were Boehm, Clauss, Fischer and Hofmann who did experiments with graphite oxide, that was exfoliated in diluted alkaline solution. Such conditions lead to graphene oxide, and they used hydrazine hydrate as reducing agent to yield reduced graphene oxide that consisted of 2-3 layers in average according to their analysis. This does not exclude single layers and single reduced graphene oxide was very likely observed by electron microscopy. Further their preparation method is now known to yield single sheets of reduced graphene oxide. But reduced graphene oxide is graphene with a variety of defects and only graphene free from defects exhibits exceptional physics (Boehm et al., 1962).

The next step was made by the group of Ruoff in 1999, who manipulated graphite islands by atomic force microscopy and they dangled the isolation of graphene (Lu et al., 1999). In 2003 it were Gan et al. in Beijing who exfoliated the single layer graphene from graphite by STM and verified it (Gan et al., 2003). In 2004 few layer graphene, about three layers, was grown from $\mathrm{SiC}$ and the beginning was laid for the application of graphene and few layer graphene in electronic devices (Berger et al., 2004).

The simplest method for preparing high quality graphene and the breakthrough for the discovery of the properties of graphene was published in 2004 by the Group of Geim in Manchester. They used adhesive tape to exfoliate graphene from graphite (Novoselov et al., 2004). Now it is possible to identify single sheets even by optical methods using e.g. $300 \mathrm{~nm}$ $\mathrm{SiO}_{2}$ dielectric on $\mathrm{Si}$ substrates (Casiraghi et al., 2007; Roddaro et al., 2007).

\section{Preparation methods for graphene}

In the literature, it is not strictly separated between graphene, few layer graphene, reduced graphene oxide, graphene with a certain amount of defects and perfect graphene. The term graphene is generally used for one layer of carbon with a high carbon content, generally higher than $90 \%$.

\subsection{Mechanical cleavage}

One of the best qualities of isolated graphene is yielded by mechanical exfoliation using adhesive tape to overcome the van der Waals interaction energy for exfoliation. This exfoliation process must be repeated several times to obtain few layered graphene sheets that can be transferred on the desired substrate by gently pressing the tape. This method suffers from scaling problems and only $\mu \mathrm{m}^{2}$ pieces can be prepared but this method is essential for fundamental studies. Besides, the obtained graphene is contaminated by the glue and must be removed before usage. 


\subsection{Decomposition of silicon carbide}

A high temperature process is described using silicon carbide wafer in high vacuum. At about $1300{ }^{\circ} \mathrm{C}$ silicon sublimates and graphitization of the remaining carbon can take place to form graphene. At higher temperatures of about $1650{ }^{\circ} \mathrm{C}$ the decomposition takes also place in an argon atmosphere and graphene can be obtained. The quality is slightly worse than for mechanically processed material as it was judged from charge carrier mobility (Soldano et al., 2010).

\subsection{Graphitization of small molecules}

Another method is the growth of graphene on metal surfaces from small molecules. Mostly used molecules are methane and acetylene. Platinum, ruthenium, iridium, nickel or copper are suitable substrates. This method also needs high temperatures in the range of $900-1100{ }^{\circ} \mathrm{C}$. There is also a strong interaction between graphene and the metal surface, making an etching process necessary to remove the metal and make it possible to transfer graphene to another substrate (Soldano et al., 2010). In a recent approach copper with large grain was used as the substrate and a 30-inch graphene sheet was prepared (Bae et al., 2010). A methane/hydrogen mixture was used to grow graphene at $1000^{\circ} \mathrm{C}$. Several transfer steps were necessary to isolate graphene. First, a transfer tape was applied on graphene and then copper was etched away. Second, graphene was transferred to a PET substrate at elevated temperatures. This process can be repeated to prepare few layer graphene on arbitrary substrates.

In the group of Muellen graphenes are prepared in a bottom-up approach by chemical total synthesis. These nano-graphenes are processible, e.g. hexadodecyl-substituted superphenalene $\mathrm{C}_{96}-\mathrm{C}_{12}$. In a second step, annealing at $1100{ }^{\circ} \mathrm{C}$ is necessary for graphitization to gain an electrically conductive material (Wang et al., 2008b).

\subsection{Exfoliation of graphite}

In another approach graphite is the starting material and in the first step an intercalation compound is prepared. Commonly, nitric or sulphuric acid are suitable for the intercalation of graphite. As a consequence, the sheet distance increases and it becomes easier to intercalate other reagents that make the exfoliation possible. A thermal shock, heating to $800-1100{ }^{\circ} \mathrm{C}$, causes the decomposition of the intercalated acid and the exfoliation takes place. Such materials can be dispersed as single layers in suitable solvents, as N-methyl-2pyrrolidon, dimethylformamide, 1,2-dichloroethane or chloroform. Some examples are available were polymeric stabilizer or surfactants (e.g. sodium dodecylbenzenesulfonate) were used to increase the concentration of dispersed graphene. In almost all examples the dispersions are sonicated to increase single layer yield or to prevent aggregation (Compton \& Nguyen, 2010; Cravotto \& Cintas, 2010; Soldano et al., 2010).

Besides, potassium intercalated graphite $\mathrm{KC}_{8}$ is a prominent stage- 1 intercalation compound that readily exfoliates in N-methyl-2-pyrrolidon without sonication to form stable dispersions (Vallés et al., 2008). Sonication is also not necessary if graphite is treated with chlorosulfonic acid for several days. That solvent turned out to be a suitable solvent that causes spontaneous exfoliation to graphene sheets (Behabtu et al., 2010).

\subsection{Reduction of graphene oxide}

Another precursor compound of graphene is graphene oxide. The oxidation of graphite to graphene oxide provides the possibility of applying a rich chemistry to that class of material 
that is not possible in other methods. Another advantage is the possibility for processing graphene oxide or chemically functionalized graphene oxide dispersions from solution to match common coating techniques. In addition, using graphene oxide makes large-scale production of electroactive materials possible. Graphene oxide itself is not electrically conductive and a further processing step is necessary to recover the conductivity. A broad set of reductive agents is available for the reduction or deoxygenatation of graphene oxide derivatives. Examples are hydrazine, hydrazine monohydrate, dimethylhydrazine, sodium boron hydride, sodium hydride, hydrochinone, p-phenylene diamine, strongly alkaline solution, supercritical water, $\mathrm{H}_{2}$-plasma, electrochemical reduction, photocatalytic reduction and others (Eda \& Chhowalla, 2010). In addition, it is possible to reduce graphene oxide in solution, e.g. water. Since reduced graphene oxide aggregates in aqueous solution a stabilizer is necessary to form reduced graphene dispersions. That can be achieved by adding surfactants, e.g. sodium 4-styrenesulfonate or ionic liquids (Zhang et al., 2010). The addition of base to deprotonate carboxylic acids of graphene oxide causes electrostatic repulsion and thus stabilization during reduction. Non-covalent interactions of aromatic molecules can also be used to stabilize reduced graphene oxide, e.g. pyrene-1-sulfonic acid. Furthermore, graphene oxides functional groups can react with a variety of reagents to form covalent bonds to amines, alcohols and others. These new functional groups remain stable during reduction and help stabilizing dispersions (Compton \& Nguyen, 2010; Loh et al., 2010).

\subsection{The structure of reduced graphene oxide}

The oxidation/reduction process of graphene oxide is not a reversible one and the honeycomb lattice is not recovered. Amongst other properties, the electrical conductivity of reduced graphene oxide lags behind graphene prepared by mechanical cleavage or chemical vapour deposition (CVD). The reason for this is the defective structure of reduced graphene oxide. Gómez-Navarro et al. utilized high-resolution transmission electron microscopy at $80 \mathrm{keV}$ to visualize the structure of reduced graphene oxide at atomic resolution. In this case hydrogen plasma was used for the reduction followed by annealing.
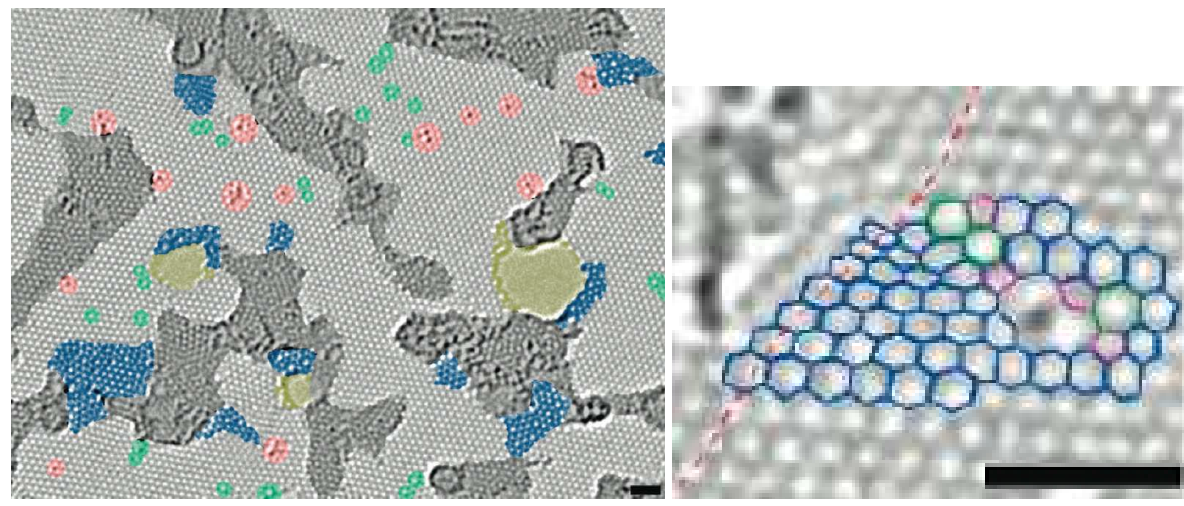

Fig. 3. A) Structure of reduced graphene oxide; grey: preserved structure, dark grey: contaminated area, yellow: holes with edge reconstructions, blue: distorted region, red: added or substituted atoms, green: isolated single bond rotations or dislocation cores. B) distorted region; scale bar $1 \mathrm{~nm}$ (Gómez-Navarro et al., 2010). Reprinted with permission from Gómez-Navarro et al., 2010. Copyright 2010 American Chemical Society. 
Hence, different types of defects can be distinguished. Beside holes and reorganized edges (yellow) preserved regions of the original graphene lattice (grey) could be identified. These regions are sometimes disturbed by adjacently defects due to isolated pentagon/heptagon defects (green) and isolated defects caused by added or substituted atoms (red). Moreover, there are contaminated regions (dark grey) and distorted regions (blue). Especially these distorted regions cause strain combined with in- and out-of-plane defects. In addition, the Bernal $A B$ stacking is not preserved and turbostratic stacking is favoured for few layer reduced graphene oxide (Gómez-Navarro et al., 2010).

Keeping the different preparation methods in mind, it is conceivable that the electrical properties of the obtained graphene are different. Hence, the quality of graphene and few layer graphene is dependent on the number and type of defects. One can image the manifold possibilities for oxidation and reduction procedures and the involved electrical conductivity. The described preparation methods are used for transparent and electrically conductive thin films (TCFs). The performance of these thin films is very different with respect to transparency and sheet resistance. Because of that, methods were developed to characterize the electrical performance of reduced graphene oxide, graphene and other electrically conductive and transparent materials.

\section{Characterization of transparent and electrically conductive thin films}

\subsection{Determination of the electrical conductivity and transparency}

For the characterization of electrically conductive materials it is necessary to measure current and voltage at a given distance to determine the resistance of the sample. The twopoint probe measurement uses this method but the measured value includes e.g. the contact resistance between the metal electrode and the sample. To eliminate such uncertainties the four-point probe method is used (Topsoe, 1968).

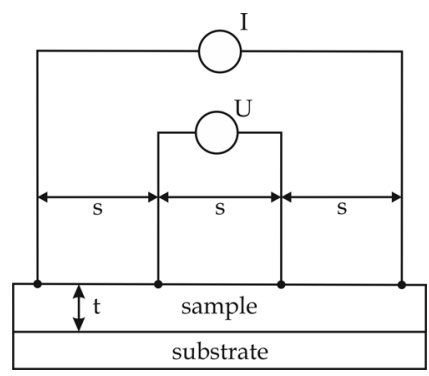

U: measured voltage

I: measured current

s: probe distance

$\mathrm{t}$ : thickness of the sample

Fig. 4. Illustration of the four-point probe measurement setup

If the four probes are equal in distance and the sheet thickness is much smaller than the probe distance, the sheet resistance can be expressed with the following term:

$$
R_{s}=\frac{\pi}{\ln 2} \cdot \frac{U}{I}
$$

$\mathrm{R}_{\mathrm{s}}$ : sheet resistance; $\mathrm{U}$ : voltage; I: current.

With the help of the sheet resistance and measurement of the thickness of the sample it is possible to calculate the electrical conductivity. It is the reciprocal of the product of the sheet resistance and the thickness of the sample given in $\mathrm{S} / \mathrm{cm}$. 


$$
\sigma=\frac{1}{R_{s} \cdot t}
$$

$\sigma$. electrical conductivity; $\mathrm{R}_{\mathrm{s}}$ : sheet resistance; $\mathrm{t}$ : thickness of the sample.

For characterizing electrically conductive and transparent materials it is certainly necessary to determine the transparency what is accomplished by UV-Visible spectroscopy. For optical applications it is reasonable to measure the transparency in the visible region. Hence, it is best measured at the wavelength where the human eye is most sensitive, at $550 \mathrm{~nm}$.

\subsection{Comparing the performance of transparent and conductive materials}

On the one hand the sheet resistance is measured in $\Omega$ or in $\Omega /$ sq to illustrate the given surface resistance. On the other hand the transparency is given in $\%$ or $\% \mathrm{~T}$. It is obvious to combine both independent parameters to get one value for comparison. In 1972 Fraser \& Cook prepared ITO coatings and introduced a figure of merit (FOM) to compare the performance of differently prepared coatings (Fraser \& Cook, 1972).

$$
F O M_{1}=\frac{T}{R_{s}}
$$

The disadvantage of this definition is that the performance is the same for a coating of $95 \% \mathrm{~T} / 95 \Omega$ and $85 \% \mathrm{~T} / 85 \Omega$. The determined $\mathrm{FOM}_{1}$ is 1 in both cases but certainly it is not. Spath et al. described a further improvement in 2006. The advantage is using the logarithm of the transparency for the determination of the figure of merit (Spath et al., 2006). Budhadipta et al. described a similar method in 2009. In this case the sheet resistance and the logarithm of the transmission are multiplied.

$$
F O M_{2}=-\ln \left(\frac{I}{I_{0}}\right) \cdot R_{s}=\rho \varepsilon
$$

$\varepsilon$ : extinction coefficient; $\rho$ : material resistivity.

This FOM is the product of the material resistivity and the extinction coefficient of the material and both of them are generally not known.

For the example above this means a $\mathrm{FOM}_{2}=4.87$ for $95 \% \mathrm{~T} / 95 \Omega$ and a $\mathrm{FOM}_{2}=13.8$ for $85 \% \mathrm{~T} / 85 \Omega$. In this case the smaller the value of the FOM the higher is the performance and the better performance of the first example becomes evident.

The "conductivity of transparency" or "transparence conductance" was defined in 2009, a similar approach compared to Budhadipta et al. but utilizing the transparency of a reference material to determine an ideal thickness of the sample (Eigler, 2009).

In 2008, Nair et al. published the transparency of single and few layer graphene. Each layer absorbs $2.3 \%$ of white light and the Lambert-Beer law is fulfilled, even if it is defined for low concentrations where molecules do not interact with each other. According to equation 2 and using graphene as the ideal reference material the conductivity of transparency can be defined as the reciprocal of the sheet resistance and the ideal thickness of the sample.

$$
\sigma_{g t}=\frac{1}{R_{s} \cdot t_{\text {ideal }}}
$$


$\sigma_{\mathrm{gt}}$ : conductivity of transparency based on graphene at $550 \mathrm{~nm} ; \mathrm{R}_{\mathrm{s}}$ : sheet resistance of a transparent conductive sample; $t_{\text {ideal }}$ : thickness of the sample based on the transparency of the sample and the ideal sheet distance in graphite.

The ideal thickness is that one that corresponds to the transparency of graphene.

Differently prepared coatings consisting of different qualities of graphene should become comparable, even if the thickness of the sample is unknown. First of all, the absorption coefficient is calculated using the Bouguer-Lambert law that is given by:

$$
\lg \left(\frac{I}{I_{0}}\right)=\varepsilon c t ; \quad \varepsilon^{*} c=\varepsilon_{\text {graphene }}
$$

$\varepsilon^{*}$ : extinction coefficient; c: concentration; $\mathrm{t}$ : pathway of the light; $\varepsilon_{\text {graphene: absorption }}$ coefficient of graphene; I: transmission in $\%$; $\mathrm{I}_{0}$ : transmission (100\%: no absorption).

The absorption coefficient is dependent on the intensity change of the light, the length of the pathway, and the concentration. For graphene the concentration is constant. In this case there is no dependence on the concentration because the perfect graphene structure has no variable concentration. Further, the sheet distance of graphite is well known to be $335 \mathrm{pm}$. From these data it is possible to calculate the absorption coefficient of graphene to $301655 \mathrm{~cm}^{-1}$ by Eq. (7):

$$
\varepsilon_{\text {graphene }}=\frac{-\lg \left(\frac{I}{I_{0}}\right)}{t_{\text {graphite }}}=\frac{-\lg \left(\frac{97.7 \%}{100 \%}\right)}{3.35 \cdot 10^{-8} \mathrm{~cm}}=301655 \mathrm{~cm}^{-1}
$$

Even if the examined transparent sample is not perfect an ideal thickness can be calculated from Eq. (8):

$$
t_{\text {ideal }}=\frac{-\lg \left(\frac{I}{I_{0}}\right)}{\varepsilon_{\text {graphene }}}
$$

It corresponds to the thickness of ideal graphene sheets and in the case of several sheets they are also packed perfectly. Finally, the conductivity of transparency of a transparent sample can be calculated by the combination of equation 6 and 9:

$$
\sigma_{g t}=\frac{\varepsilon_{\text {graphene }}}{-\lg \left(\frac{I}{I_{0}}\right) \cdot R_{s}}=\frac{301655 \mathrm{~cm}^{-1}}{-\lg \left(\frac{I}{100 \%}\right) \cdot R_{s}}
$$

It should be noted that $\sigma_{g t}$ differs from the conductivity $\sigma$ due to imperfections, e.g. interlayer distance, defects, intercalation of impurities or doping that can generally influence optical and electrical properties. Nevertheless, from a practically point of view, the real thickness of a transparent coating is not so important. For the example above this means $\sigma_{g t}=1.4 \times 10^{5} \mathrm{~S} / \mathrm{cm}$ for $95 \% \mathrm{~T} / 95 \Omega$ and $\sigma_{g t}=5.0 \times 10^{4} \mathrm{~S} / \mathrm{cm}$ for $85 \% \mathrm{~T} / 85 \Omega$.

For comparing different electrically conductive and transparent thin films the figure of merit approach using the logarithm of the transparency is sufficient. In our example it is clear that 
the performance of the first one is almost three times higher compared to the second one. The advantage of using graphene as the reference material is to get a conductivity value that can be compared with graphene.

Blake et al. specify the sheet resistance of undoped graphene to about $6000 \Omega$, which results from one conductivity quantum per species of charge carrier (Blake et al., 2008). Moreover one sheet absorbs $2.3 \%$ of white light. From these values $\sigma_{g t}$ can be calculated to $5000 \mathrm{~S} / \mathrm{cm}$. The $\sigma_{g t}$ is not limited to this value, e.g. if any coating absorbs $2.3 \%$ of light but the sheet resistance is $500 \Omega$ a $\sigma_{g t}$ of $6.0 \times 10^{4} \mathrm{~S} / \mathrm{cm}$ is obtained, which means that the conductivity of that coating is 12 times higher than that of a single graphene sheet. Because of that, the conductivity of transparency based on graphene is not limited to carbon materials. It can be extended to all transparent and conductive materials. As a consequence their conductivity is based on the conductivity and transparency of graphene and that is true at least for carbonbased materials that derive from graphene. Now it is possible to obtain not only a figure of merit but also a conductivity that can be compared with the bulk conductivity of other materials with knowing the transparency of the sample and without knowing the thickness. In the following, this concept is applied to several recently published examples dealing with graphene and other transparent materials.

\subsection{Correlation between the bulk conductivity and the conductivity of transparency for chemically derived graphene}

In Table 1 typical values of $\sigma_{g t}$ are summarized that result from 80,90 , and $98 \% \mathrm{~T}$ at different sheet resistances to illustrate $\sigma_{g t}$ values. E.g. a $\sigma_{g t}$ of about $3000 \mathrm{~S} / \mathrm{cm}$ is necessary to prepare coatings with a sheet resistance of $1000 \Omega$ with $80 \% \mathrm{~T}$.

\begin{tabular}{|l|c|c|c|c|c|c|c|c|}
\hline $\mathrm{R}_{\mathrm{s}}(\Omega)$ & 10 & 100 & 500 & $10^{3}$ & $10^{4}$ & $10^{5}$ & $10^{6}$ & $10^{7}$ \\
\hline $\begin{array}{l}\sigma_{g t}(\mathrm{~S} / \mathrm{cm}) \\
\text { at } 80 \% \mathrm{~T}\end{array}$ & $3.1 \times 10^{5}$ & $3.1 \times 10^{4}$ & $6.2 \times 10^{3}$ & $3.1 \times 10^{3}$ & $3.1 \times 10^{2}$ & 31 & 3.1 & 0.31 \\
\hline $\begin{array}{l}\sigma_{g t}(\mathrm{~S} / \mathrm{cm}) \\
\text { at } 90 \% \mathrm{~T}\end{array}$ & $6.6 \times 10^{5}$ & $6.6 \times 10^{4}$ & $1.3 \times 10^{4}$ & $6.6 \times 10^{3}$ & $6.6 \times 10^{2}$ & 66 & 6.1 & 0.61 \\
\hline $\begin{array}{l}\sigma_{g t}(\mathrm{~S} / \mathrm{cm}) \\
\text { at } 98 \% \mathrm{~T}\end{array}$ & $3.4 \times 10^{6}$ & $3.4 \times 10^{5}$ & $6.9 \times 10^{4}$ & $3.4 \times 10^{4}$ & $3.4 \times 10^{3}$ & $3.4 \times 10^{2}$ & 34 & 3.4 \\
\hline
\end{tabular}

Table $1 . \sigma_{g t}$ at a transparency at 80,90 and $98 \% \mathrm{~T}$ in dependence of $\mathrm{R}_{\mathrm{s}}$.

Becerril et al. published a study of differently treated graphene oxide (Table 2). Graphene oxide itself is highly transparent and $\sigma_{g t}=5.7 \times 10^{-5} \mathrm{~S} / \mathrm{cm}$ that is about one order of magnitude higher than the bulk conductivity $\sigma_{g t}=3.7 \times 10^{-6} \mathrm{~S} / \mathrm{cm}$. If graphene oxide is reduced with hydrazine, the conductivity increases by four orders of magnitude and $\sigma_{g t}$ increases about three orders of magnitude. After treatment with hydrazine at $400{ }^{\circ} \mathrm{C}$ the conductivity and $\sigma_{g t}$ differ by a factor of about 3 . After heating GO in vacuum at $1100{ }^{\circ} \mathrm{C}$ the conductivity increases to $1.7 \times 10^{2} \mathrm{~S} / \mathrm{cm}$ and the $\sigma_{g t}$ is 6.5 times higher. In general the $\sigma_{g t}$ values are higher than the $\sigma$ values, possibly due to an increased transparency caused by, e.g. residual functional groups or possibly doping (Becerril et al., 2008).

According to investigations from Mattevi et al. the transparency of graphene oxide changed from 87 to $84 \%$ during annealing between 200 and $1000{ }^{\circ} \mathrm{C}$, a change of about $4 \%$ (Mattevi et al., 2009). Assumedly, the difference between the bulk conductivity and the conductivity 
of transparency for few layer coatings of reduced graphene oxide is attributed to the nonideal sheet distance. It is well known that the sheet distance for reduced graphene oxide is higher, about $0.8 \mathrm{~nm}$, due to residual functional groups or impurities, compared to few layer graphene $(0.34 \mathrm{~nm})$. So, the difference in the sheet distance should correlate well to the difference between bulk conductivity and the conductivity of transparency.

\begin{tabular}{|l|c|c|c|c|}
\hline GO treated & not reduced & hydrazine & hydrazine $400^{\circ} \mathrm{C}$ & vacuum $1100{ }^{\circ} \mathrm{C}$ \\
\hline $\mathrm{t}(\mathrm{nm})$ & 9 & 5 & 3 & 8 \\
\hline$\% \mathrm{~T}(550 \mathrm{~nm})$ & 96 & 92 & 93 & 92 \\
\hline$R_{s}(\Omega)$ & $3.0 \times 10^{11}$ & $1.4 \times 10^{8}$ & $2.6 \times 10^{5}$ & 7400 \\
\hline$\sigma(\mathrm{S} / \mathrm{cm})$ & $3.7 \times 10^{-6}$ & $1.4 \times 10^{-2}$ & 13 & 170 \\
\hline$\sigma_{g t}(\mathrm{~S} / \mathrm{cm})$ & $5.7 \times 10^{-5}$ & $5.9 \times 10^{-2}$ & 37 & 1100 \\
\hline
\end{tabular}

Table 2. Comparison of the thickness, transparency, sheet resistance, conductivity and conductivity of transparency of differently treated graphene oxide (Becerril et al., 2008).

\section{The performance of chemically derived graphene}

Since 2008 the interest in conductive and transparent materials based on graphene increased and several preparation methods were developed. In many cases reduced graphene oxide was used. Moreover, chemical vapour deposition techniques and dispersed graphene are described and graphene was prepared from small molecules. Besides, graphene material was combined with several other materials to enhance the conductivity of transparency. In this chapter the performance of coatings derived from these materials will be compared with other materials as poly(3,4-ethylenedioxythiophene)/poly(4-styrenesulfonate) (PEDOT/PSS), single wall carbon nanotubes (SWCNTs), multi wall carbon nanotubes (MWCNTs), silver nanowires (AgNWs) and indium tin oxide (ITO).

\subsection{The performance of reduced and low temperature annealed graphene oxide}

Graphene oxide is a long known material and the preparation is well controlled. The great advantage of graphene oxide over other materials is its versatility that is reflected in more

\section{Reduced/Annealed Graphene Oxide}

(RT-400 ${ }^{\circ} \mathrm{C}$ )

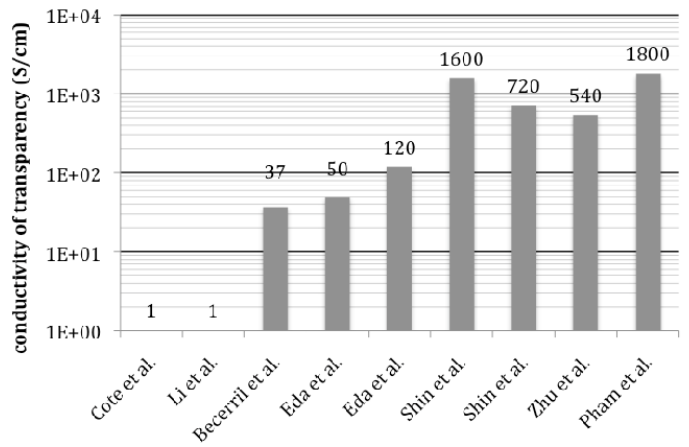

Fig. 5. Comparison: conductivity of transparency for reduced and annealed graphene oxide below $550^{\circ} \mathrm{C}$. 
than thousand publications since 2009 from many disciplines. One discipline is its possibility of processing graphene oxide in thin films with a thickness from one layer to few layers that remain transparent upon reduction.

Thin films of graphene oxide can be deposited on transparent substrates, as glass by common techniques, e.g. by spin- or bar-coating, drop-casting, dipping, filtration and transfer printing.

In 2008 Cote et al. prepared Langmuir-Blodgett monolayer films from graphene oxide. Moreover they succeeded in preparing an overpacked film to provide a conduction pathway and reduced it by hydrazine vapour to yield a conductive film with a transparency of more than $95 \%$ (Cote et al., 2009).

\begin{tabular}{|l|c|c|c|}
\hline Reference & $\% \mathrm{~T}(550 \mathrm{~nm})$ & $\mathrm{R}_{\mathrm{s}}(\Omega)$ & $\sigma_{g t}(\mathrm{~S} / \mathrm{cm})$ \\
\hline Cote et al. & 95 & $1.9 \times 10^{7}$ & 1 \\
\hline Li et al. & 96 & $2.0 \times 10^{7}$ & 1 \\
\hline Becerril et al. & 93 & $2.6 \times 10^{5}$ & 37 \\
\hline Eda et al. & 87 & $1.0 \times 10^{5}$ & 50 \\
\hline Eda et al. & 65 & $1.4 \times 10^{4}$ & 120 \\
\hline Shin et al. & 83 & 2300 & 1600 \\
\hline Shin et al. & 83 & 5200 & 720 \\
\hline Zhu et al. & 96 & $3.2 \times 10^{4}$ & 540 \\
\hline Pham et al. & 84 & 2200 & 1800 \\
\hline
\end{tabular}

Table 4. Comparison: transparency, sheet resistance and conductivity of transparency for reduced and annealed graphene oxide below $550{ }^{\circ} \mathrm{C}$.

The conductivity of transparency was about $1 \mathrm{~S} / \mathrm{cm}$. Li et al. who reduced graphene oxide in an alkaline dispersion achieved a similar performance and spray coated reduced graphene oxide on glass ( $\mathrm{Li}$ et al., 2008a). Becerril et al. deposited graphene oxide on glass slides and used hydrazine vapour for the reduction and annealed at $400{ }^{\circ} \mathrm{C}$. As a consequence, the conductivity of transparency increased to $37 \mathrm{~S} / \mathrm{cm}$ (Becerril et al., 2008). Eda et al. also used the combination of hydrazine reduction and thermal annealing and achieved $50 \mathrm{~S} / \mathrm{cm}$. A subsequent $\mathrm{SOCl}_{2}$ p-type doping procedure increased the performance to $120 \mathrm{~S} / \mathrm{cm}$ (Eda et al., 2008a; Eda et al., 2008b). Shin et al. utilized sodium boron hydride as reducing agent. They dipped coated glass in a solution of the reducing agent for several days and they achieved a $\sigma_{g t}$ of $720 \mathrm{~S} / \mathrm{cm}$, which could be improved to $1600 \mathrm{~S} / \mathrm{cm}$ by adding a layer of $\mathrm{AuCl}_{3}$ as dopant (Shin et al., 2009a; Shin et al., 2009b). An assumedly highly ordered film was obtained by $\mathrm{Zhu}$ et al. who utilized the air-liquid interface to isolate few layer hydrazine reduced graphene oxide from the liquid surface and transferred it on glass. Despite the low temperature process the conductivity of transparency is about $500 \mathrm{~S} / \mathrm{cm}$ (Zhu et al., 2009). An even better performance was achieved in 2010 by Pham et al. who described a spray-coating procedure for the coating of preheated glass. Hence, glass slides were heated to $240{ }^{\circ} \mathrm{C}$ and a hydrazine treated graphene oxide dispersion diluted in water/ethanol was sprayed on it. The conductivity of transparency can be calculated to $1800 \mathrm{~S} / \mathrm{cm}$, one of the highest values for reduced graphene oxide treated at a moderate temperature (Pham et al., 2010).

These examples demonstrate the increasing performance of reduced graphene oxide as transparent and conductive coatings. This development just started a few years ago and 
there is currently tremendous research done. But even if the performance increase from 1 to almost $2000 \mathrm{~S} / \mathrm{cm}$ is impressive it becomes evident that the chemical distortions caused by the oxidation and reduction procedure limits the performance. Moreover the charge transport is certainly another one compared to graphene obtained by mechanical cleavage. Using such coatings e.g. for touch screen application the minimum demands are $3000 \mathrm{~S} / \mathrm{cm}$ or even more. To further improve the quality of graphene derived from graphene oxide a high temperature-annealing step is often desired.

\subsection{The performance of reduced and annealed graphene oxide}

To enhance the properties of reduced graphene oxide a high temperature-annealing step is often involved in the preparation of transparent and conductive coatings. In most cases quartz glass is necessary to apply temperatures within the range of $700-1100^{\circ} \mathrm{C}$.

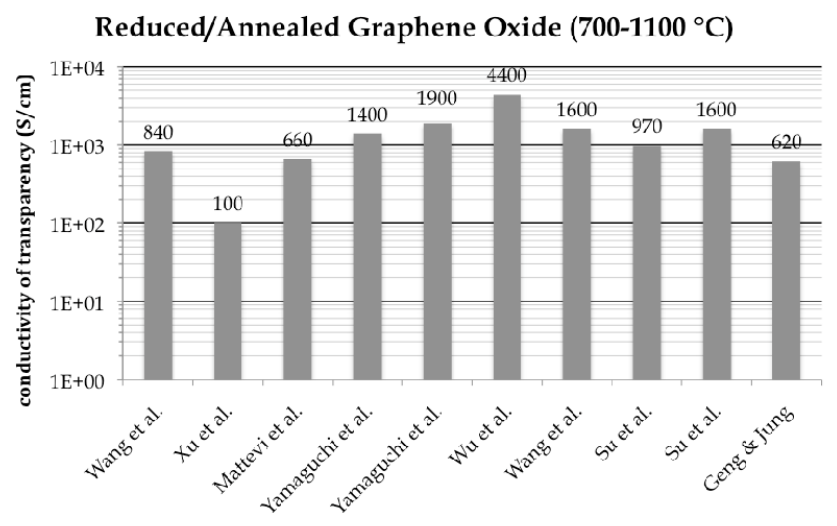

Fig. 6. Comparison: conductivity of transparency for reduced and annealed graphene oxide between 700 and $1100^{\circ} \mathrm{C}$.

\begin{tabular}{|l|c|c|c|}
\hline Reference & $\% \mathrm{~T}(550 \mathrm{~nm})$ & $\mathrm{R}_{\mathrm{s}}(\Omega)$ & $\sigma_{g t}(\mathrm{~S} / \mathrm{cm})$ \\
\hline Wang et al. & 63 & 1800 & 840 \\
\hline Xu et al. & 69 & $1.8 \times 10^{4}$ & 100 \\
\hline Mattevi et al. & 84 & 6000 & 660 \\
\hline Yamaguchi et al. & 81 & 2400 & 1400 \\
\hline Yamaguchi et al. & 70 & 1000 & 1900 \\
\hline Wu et al. & 82 & 800 & 4400 \\
\hline Wang et al. & 80 & 2000 & 1600 \\
\hline Su et al. & 70 & 2000 & 970 \\
\hline Su et al. & 68 & 1100 & 1600 \\
\hline Geng \& Jung & 80 & 5000 & 620 \\
\hline
\end{tabular}

Table 4. Comparison: transparency, sheet resistance and conductivity of transparency for reduced and annealed graphene oxide between 700 and $1100{ }^{\circ} \mathrm{C}$. 
In 2007/2008 Wang et al. published a transparent and conductive electrode with the scope of using it for solar cells. Therefore graphene oxide was annealed at $1100{ }^{\circ} \mathrm{C}$ (Wang et al., 2008a) and the conductivity increased five times during heating from 700 to $1100{ }^{\circ} \mathrm{C}$ and a final conductivity of transparency of $840 \mathrm{~S} / \mathrm{cm}$ was obtained. However $\mathrm{Xu}$ et al. annealed hydrazine reduced graphene oxide at $700{ }^{\circ} \mathrm{C}$ and a moderate $\sigma_{g t}$ of $100 \mathrm{~S} / \mathrm{cm}$ was obtained (Xu et al., 2010). In 2009 Mattevi et al. annealed graphene oxide coatings at $1100{ }^{\circ} \mathrm{C}$ in a reducing atmosphere $\left(\mathrm{H}_{2} / \mathrm{Ar}\right.$ ) and achieved $660 \mathrm{~S} / \mathrm{cm}$ (Mattevi et al., 2009). A better performance was obtained in 2010 from Yamaguchi et al. for spin-coated graphene oxide on $300 \mathrm{~mm}$ wafers followed by either hydrazine reduction and thermal annealing or thermal annealing only. It was stated that a similar performance is obtained and the conductivity of transparency can be calculated to 1400 and $1900 \mathrm{~S} / \mathrm{cm}$, respectively for different samples. A much higher performance of $4400 \mathrm{~S} / \mathrm{cm}$ was achieved by Wu et al. after annealing graphene oxide three hours at $1100{ }^{\circ} \mathrm{C}$. It seems that a certain amount of defects could be repaired during that elongated thermal annealing procedure (Wu et al., 2010). Next, Wang et al. first reduced graphene oxide in alkaline solution by hydrazine and prepared thin films by filtration followed by transferring them on quartz glass and subsequent annealing at $1100{ }^{\circ} \mathrm{C}$ for 30 minutes. In this case the conductivity of transparency was $1600 \mathrm{~S} / \mathrm{cm}$ (Wang et al., 2010). Another approach was to reduce a mixture of graphene oxide and pyrene-1-sulfonic acid sodium salt prior to hydrazine reduction followed by thermal annealing of thin films at $1000{ }^{\circ} \mathrm{C}$. The anionic pyrene derivative acts first as a stabilizing agent and during thermal annealing as a nonographene material that can be graphitized. Indeed an increased performance from 970 to $1600 \mathrm{~S} / \mathrm{cm}$ is found due to the addition of a nanographene derivative ( $\mathrm{Su}$ et al., 2009). A similar approach is described by Geng \& Jung who used the tetrasulfonated porphrin (TPPS) as stabilizing agent. Their transparent films were annealed at $800{ }^{\circ} \mathrm{C}$ resulting in a conductivity of transparency of $620 \mathrm{~S} / \mathrm{cm}$ (Geng \& Jung, 2010).

In every case slightly different preparation conditions for graphene oxide are described and there are many parameters altered from example to example. Some of the approaches exhibit advantages in terms of processing others benefit from an increased performance. Evident is the high performance from $\mathrm{Wu}$ et al. who annealed for three hours and yielded a performance close to pristine undoped graphene. The performance of the other examples is similar to reduced graphene oxide that was processed at a much lower temperature.

\subsection{The performance of graphene obtained from graphite}

The processing of graphene oxide is a versatile method, but due to imperfections occuring during oxidation and reduction the performance lags behind prisitine graphene. Hence, researcher try to avoid oxidation of graphite and prefer direct processing. One essential challenge is the solubilization and exfoliation of graphite to single layers.

Blake et al. did not solubilize graphite and their approch is not a chemical one, but they used mechanical exfoliation to obtain graphene directly from graphite. For undoped graphene $\sigma_{g t}$ of about $5000 \mathrm{~S} / \mathrm{cm}$ was found and they demonstrated a dramatically increased performance to $8.6 \times 10^{4} \mathrm{~S} / \mathrm{cm}$ due to doping by polyvinyl alcohol (Blake et al., 2008). These promising results make it attractive to utilize graphite without oxidation. The drawback is the insolubility of graphite in water and common organic solvents that has to be overcome. In 2008 Hernandez et al. demonstrated the dispersibility of graphite in N-methyl-2pyrrolidone (NMP) upon sonication and they yielded graphene and few layer graphene. 


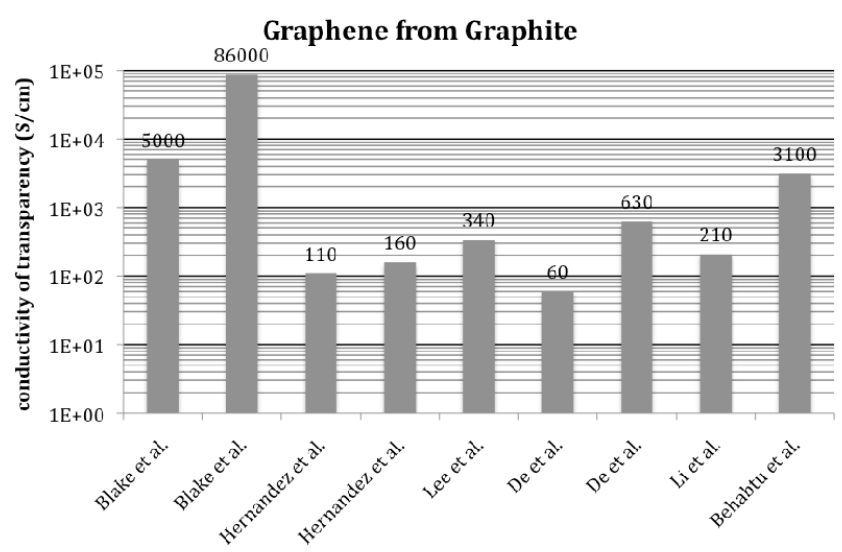

Fig. 7. Comparison: conductivity of transparency for transparent coatings derived from exfoliated graphite.

\begin{tabular}{|l|c|c|c|}
\hline Reference & $\% \mathrm{~T}(550 \mathrm{~nm})$ & $\mathrm{R}_{\mathrm{S}}(\Omega)$ & $\sigma_{g t}(\mathrm{~S} / \mathrm{cm})$ \\
\hline Blake et al. & 98 & 6000 & 5000 \\
\hline Blake et al. & 98 & 400 & $8.6 \times 10^{4}$ \\
\hline Hernandez et al. & 42 & 7100 & 110 \\
\hline Hernandez et al. & 42 & 5100 & 160 \\
\hline Lee et al. & 79 & 8500 & 340 \\
\hline De et al. & 68 & $3.0 \times 10^{4}$ & 60 \\
\hline De et al. & 76 & 4000 & 630 \\
\hline Li et al. & 85 & $2.0 \times 10^{4}$ & 210 \\
\hline Behabtu et al. & 80 & 1000 & 3100 \\
\hline
\end{tabular}

Table 5. Comparison: transparency, sheet resistance and conductivity of transparency of transparent coatings derived from exfoliated graphite.

Despite the concentration of graphene in NMP was $0.01 \mathrm{mg} / \mathrm{ml}$ only, it was possible to prepare films. After annealing these films at $300{ }^{\circ} \mathrm{C}$ or in a reductive atmosphere at $250{ }^{\circ} \mathrm{C}$ the performances were 110 and $160 \mathrm{~S} / \mathrm{cm}$, respectively. Even if the quality of the deposited graphene and few layer graphene was high the performance was expected to be better and NMP trapped between the sheets was likely the reason for it (Hernandez et al., 2008). In 2010 Lee et al. described a procedure to exfoliate graphite by thermal shock at $700{ }^{\circ} \mathrm{C}$ from $\mathrm{ClF}_{3}$ intercalated graphite. In a second step that material could be dispersed in NMP and thin films were formed by filtration and a subsequent transfer process yielded thin films on the transparent substrate. In this case a conductivity of transparency of about $300 \mathrm{~S} / \mathrm{cm}$ can be calculated (Lee et al., 2010). Sodium cholate was used by De et al. as a surfactant for 
graphite and after sonication stabilized graphene and few layer graphene were obtained. Transparent and conductive films were obtained by a filtration method as well. The conductivity of transparency for as prepared films was $60 \mathrm{~S} / \mathrm{cm}$ and the performance could be enhanced to $630 \mathrm{~S} / \mathrm{cm}$ by thermal treatment at $500{ }^{\circ} \mathrm{C}$ due to assumedly reorganization (De et al., 2009b). A more sophisticated approach was done by Li et al. who used thermal shock exfoliated graphite and intercalated it with oleum. After removal of the acid the pretreated graphite was reinercalated with terabutyl ammonium ions (TBA ${ }^{+}$) in DMF with the aid of sonication. Predominantly single layers were finally obtained by sonication with a pegylated phospholipid. Transparent films were obtained with the help of LangmuirBlodgett techniques, providing a $\sigma_{g t}$ of $210 \mathrm{~S} / \mathrm{cm}$ (Li et al., 2008b). Behabtu et al. describe the best performance for transparent and electrically conductive coatings in 2010. They used chlorosulphonic acid as the solvent and observed intercalation and spontaneous exfoliation of graphite. Moreover they succeeded in preparing transparent coatings by a filtration method and the conductivity of transparency is $3100 \mathrm{~S} / \mathrm{cm}$, at least five times better compared to the other examples (Behabtu et al., 2010).

It can be seen from these examples, even if graphite is not oxidized the performance in transparent and conductive films is not much better, or even worse compared to films obtained by processing graphene oxide.

\subsection{The performance of graphene from small molecules and hybrid materials}

As described before, graphene can be obtained from graphene oxide by high temperature processes as decomposition product. Not only graphene oxide can be used as precursor compound but also other small molecules. Moreover, the combination of graphene with carbon nanotubes provides materials of very high performance.

Graphene from Small Molecules and in Hybrid Materials

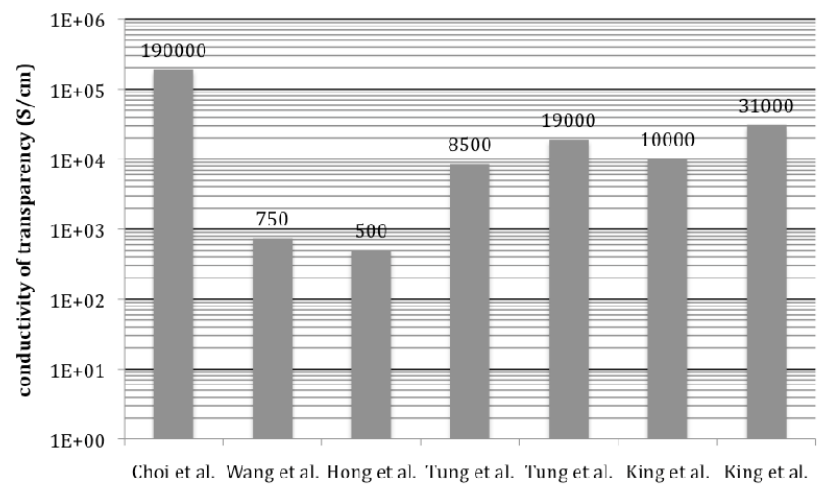

Fig. 8. Comparison: conductivity of transparency for transparent coatings derived from small molecules or hybrid materials. 


\begin{tabular}{|l|c|c|c|}
\hline Reference & $\% \mathrm{~T}(550 \mathrm{~nm})$ & $\mathrm{R}_{\mathrm{s}}(\Omega)$ & $\sigma_{g t}(\mathrm{~S} / \mathrm{cm})$ \\
\hline Choi et al. & 92 & 43 & $1.9 \times 10^{5}$ \\
\hline Wang et al. & 56 & 1600 & 750 \\
\hline Hong et al. & 84 & 8000 & 500 \\
\hline Tung et al. & 86 & 240 & $1.9 \times 10^{4}$ \\
\hline Tung et al. & 88 & 636 & 8500 \\
\hline King et al. & 80 & 300 & $1.0 \times 10^{4}$ \\
\hline King et al. & 80 & 100 & $3.1 \times 10^{4}$ \\
\hline
\end{tabular}

Table 6. Comparison: transparency, sheet resistance and conductivity of transparency of transparent coatings derived from small molecules or hybrid materials.

One exceptional example was described in 2009 by Choi et al. who used Langmuir-Blodgett techniques to prepare thin films of oleic acid. These films were deposited on substrates coated with a nickel catalyst for graphitization. The thin oleic acid films were graphitized at $500{ }^{\circ} \mathrm{C}$ and a coating with a sheet resistance of $43 \Omega$ at a transparency of $92 \%$ was obtained, what corresponds to $\sigma_{\mathrm{gt}}=1.9 \times 10^{5} \mathrm{~S} / \mathrm{cm}$ (Choi et al., 2009). The performance of that coating is up to 40 times better compared to undoped graphene and more than two times better compared to doped graphene flakes described by Blake et al. earlier. Wang et al. used the processible nanographenemolecule hexadodecyl-substituted superphenalene $C_{96}-C_{12}$ as precursor molecule for thin coatings. They prepared an electrode for solar cells by annealing at $1100^{\circ} \mathrm{C}$ with a conductivity of transparency of $750 \mathrm{~S} / \mathrm{cm}$ (Wang et al., 2008b).

Another approach is to use a combination of several transparent and conductive materials. Thus, Hong et al. combined multi wall carbon nanotubes (MWCNTs) with reduced graphene oxide. They used layer-by-layer assembly to make sheets from cationic functionalized MWCNTs and negatively charged graphene sheets with $\sigma_{\mathrm{gt}}=500 \mathrm{~S} / \mathrm{cm}$ (Hong et al., 2010). Instead of MWCNTs Tung et al. used single wall carbon nanotubes (SWCNTs) in combination with hydrazine reduced graphene oxide and they prepared coating with a performance of $8500 \mathrm{~S} / \mathrm{cm}$ and $1.9 \times 10^{4} \mathrm{~S} / \mathrm{cm}$, respectively for doped coatings (Tung et al., 2009). King et al. used SWCNTs in combination with $3 \%$ graphene obtained from sodium cholate exfoliated graphite. They prepared transparent films with a performance of about $1.0 \times 10^{4}$ and $3.1 \times 10^{4} \mathrm{~S} / \mathrm{cm}$ for acid treated films, respectively (King et al., 2010).

\subsection{The performance of graphene from chemical vapour deposition}

As shown before, it is possible to use several types of precursor molecules for graphene, as graphene oxide, nanographenes or oleic acid. CVD utilizes even smaller molecules, mostly a mixture of methane and hydrogen. Additionally, a catalyst is necessary and nickel or copper turned out to work well between 900 and $1000^{\circ} \mathrm{C}$. The advantage of CVD is the preparation of continuous graphene and few layer graphene films instead of graphene flakes as it is the case for other methods.

The CVD method is not compatible with temperature sensitive substrates, so the prepared graphene film is transferred on the desired substrate. In some cases the graphene films are not perfect and additional cracks are formed during procesing. Juang et al. described a rollto-roll process and finally a randomly stacked graphene structure is obtained with a conductivity of transparency of only 390 S/cm (Juang et al., 2010). Park et al. describe a 
procedure that yields contineous inhomogeneous films with a flake structure and $\sigma_{\mathrm{gt}}=5000 \mathrm{~S} / \mathrm{cm}$ (Park et al., 2010b). Similar results are described by Reina et al. with a conductivity of transparency of $7800 \mathrm{~S} / \mathrm{cm}$. Kim et al. and Choi et al. describe a better performance of $1.1 \times 10^{4}$ and $1.2 \times 10^{4} \mathrm{~S} / \mathrm{cm}$, respectively (Kim et al., 2009; Choi et al., 2010).

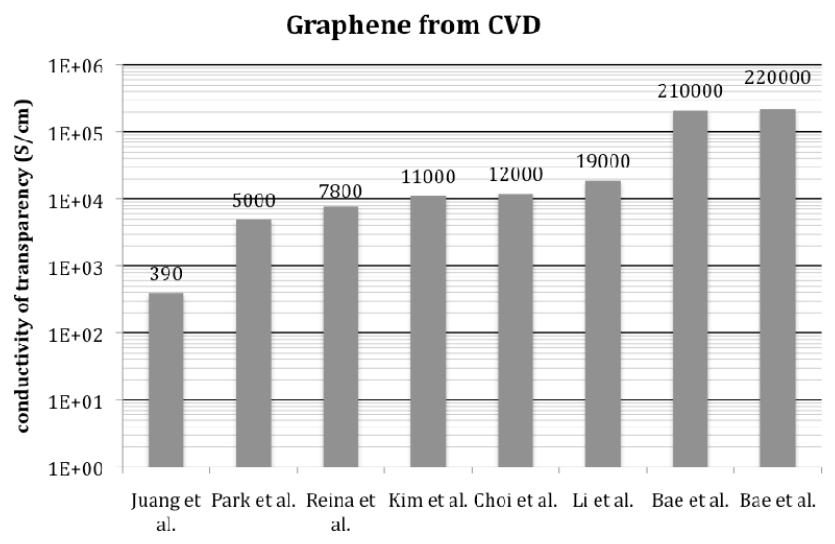

Fig. 9. Comparison: conductivity of transparency for transparent coatings from chemical vapour deposition.

These examples demonstrate the performance of the method. Even better results are obtained by switching from nickel to copper substrates. Li et al. demonstrate the crack free transfer of grown graphene films from copper to PMMA and from PMMA to the desired transparent substrate. These films with an area of $20 \mathrm{~cm}^{2}$ are highly uniform and the conductivity of transparency is $1.9 \times 10^{4} \mathrm{~S} / \mathrm{cm}$ ( $\mathrm{Li}$ et al., 2009). Bae et al. described the largest 30-inch uniform nitric acid doped graphene films with a performance of 2.1 and $2.2 \times 10^{5} \mathrm{~S} / \mathrm{cm}$, about one order of magnitude better compared to previously described results (Bae et al., 2010).

\begin{tabular}{|l|c|c|c|}
\hline Reference & $\% \mathrm{~T}(550 \mathrm{~nm})$ & $\mathrm{R}_{\mathrm{S}}(\Omega)$ & $\sigma_{g t}(\mathrm{~S} / \mathrm{cm})$ \\
\hline Juang et al. & 53 & 2800 & 390 \\
\hline Park et al. & 84 & 800 & 5000 \\
\hline Reina et al. & 88 & 700 & 7800 \\
\hline Kim et al. & 80 & 280 & $1.1 \times 10^{4}$ \\
\hline Choi et al. & 75 & 200 & $1.2 \times 10^{4}$ \\
\hline Li et al. & 90 & 350 & $1.9 \times 10^{4}$ \\
\hline Bae et al. & 90 & 30 & $2.2 \times 10^{5}$ \\
\hline Bae et al. & 97 & 125 & $2.1 \times 10^{5}$ \\
\hline
\end{tabular}

Table 7. Comparison: transparency, sheet resistance and conductivity of transparency of transparent coatings derived from chemical vapour deposition. 


\subsection{The conductivity of transparency of competing materials}

Several groups already demonstrated the superior conductivity of transparency of graphene thin films. But graphene thin films are in competition with other materials, as electrically conductive polymers derived from PEDOT, MWCNTs, SWCNTs and AgNWs.

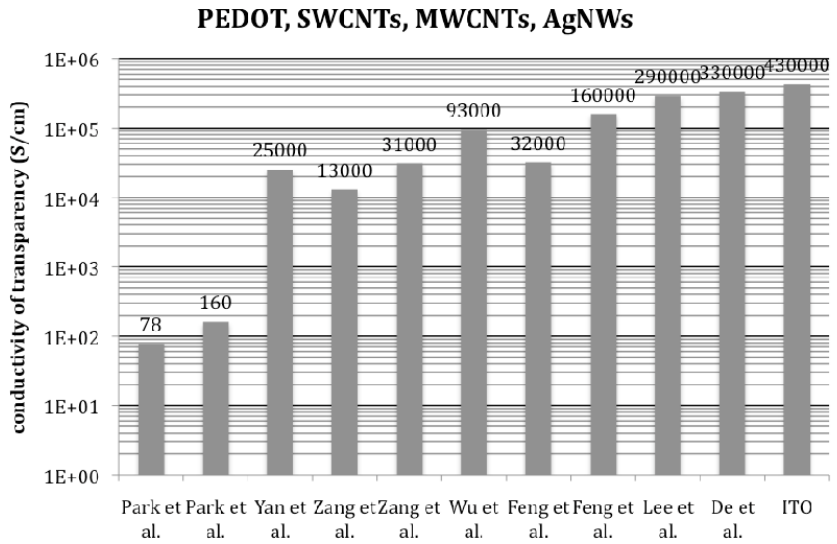

Fig. 10. Comparison: conductivity of transparency of with graphene competing transparent and conductive materials.

MWCNTs lag behind other transparent and conductive materials. Park et al. demonstrated their performance. The conductivity of transparency is $78 \mathrm{~S} / \mathrm{cm}$ (Park et al., 2010a). Even if these nanotubes are coated by $\mathrm{Au}(10 \mathrm{~nm})$, the performance doubles to only $160 \mathrm{~S} / \mathrm{cm}$. PEDOT/PSS is a bluish coloured conductive polymer and manifold used e.g. for electrostatic coatings, OLEDs or other devices. For very thin coatings the polymer appears almost colourless and transparent with a high conductivity of transparency of $2.5 \times 10^{4} \mathrm{~S} / \mathrm{cm}$ (Yan et al., 2009). A well-competing material are SWCNTs those quality varies due to the synthetic preparation method. Zhang et al. demonstrated coatings with $\sigma_{\mathrm{gt}}=1.3 \times 10^{4} \mathrm{~S} / \mathrm{cm}$ and $3.1 \times 10^{4} \mathrm{~S} / \mathrm{cm}$ for doped SWCNT coatings (Zhang et al., 2006). An even higher performance of $9.3 \times 10^{4} \mathrm{~S} / \mathrm{cm}$ was already demonstrated in 2004 (Wu et al., 2004). A notable approach was described by Feng et al. who built touch-screens from superaligned carbon nanotubes. They enhanced the transparency by laser-trimming and applied thin metal layers of typically nickel as wetting layer and gold as additional conductive layer. The performance of coatings with about $90 \%$ transparency still provide $\sigma_{g t}$ values of $3.2 \times 10^{4} \mathrm{~S} / \mathrm{cm}$ and can be improved up to impressive $1.6 \times 10^{5} \mathrm{~S} / \mathrm{cm}$ (Feng et al., 2010). Another suitable class of materials for transparent and conductive coatings are AgNWs. Silver nanowire have a typical length of $7 \mu \mathrm{m}$ and a diameter of about $100 \mathrm{~nm}$ and they can form a conductive mesh. The performance was demonstrated to be $2.9 \times 10^{5}$ and $3.3 \times 10^{5} \mathrm{~S} / \mathrm{cm}$ (Lee et al., 2008; De et al., 2009a). These values are extremely high but one must keep in mind that AgNWs form mesh-electrodes and not a uniform hole-free coating. Nevertheless, the performance is comparable to commercially available indium tin oxide (ITO) with a conductivity of transparency of $4.3 \times 10^{5} \mathrm{~S} / \mathrm{cm}$ (Sigma-Aldrich ${ }^{\circledR}$ catalog no. 576360). 


\begin{tabular}{|l|c|c|c|}
\hline Reference & $\% \mathrm{~T}(550 \mathrm{~nm})$ & $\mathrm{R}_{\mathrm{s}}(\Omega)$ & $\sigma_{s t}(\mathrm{~S} / \mathrm{cm})$ \\
\hline Park et al. & 80 & $4.0 \times 10^{4}$ & 78 \\
\hline Park et al. & 80 & $1.9 \times 10^{4}$ & 160 \\
\hline Yan et al. & 89 & 240 & $2.5 \times 10^{4}$ \\
\hline Zang et al. & 87 & 380 & $1.3 \times 10^{4}$ \\
\hline Zang et al. & 87 & 160 & $3.1 \times 10^{4}$ \\
\hline Wu et al. & 78 & 30 & $9.3 \times 10^{4}$ \\
\hline Feng et al. & 90 & 210 & $3.2 \times 10^{4}$ \\
\hline Feng et al. & 83 & 24 & $1.6 \times 10^{5}$ \\
\hline Lee et al. & 86 & 16 & $2.9 \times 10^{5}$ \\
\hline De et al. & 85 & 13 & $3.3 \times 10^{5}$ \\
\hline $\begin{array}{l}\text { Sigma-Aldrich }{ }^{\circledR} \\
\text { no. } 576360\end{array}$ & 85 & 10 & $4.3 \times 10^{5}$ \\
\hline
\end{tabular}

Table 8. Comparison: transparency, sheet resistance and conductivity of transparency of transparent coatings with graphene competing transparent and conductive materials.

\section{Summary and outlook}

It has been demonstrated that the definition of $\sigma_{g t}$ provides helpful values to compare transparent and conductive coatings on the basis of graphene as a reference material. Moreover, the common preparation methods for graphene were summarized and the performance of graphene in transparent and electrically coatings was compared. Graphene oxide is available on a large scale and the coating procedures are versatile. The modification methods for that material are manifold and upon reduction a conductive graphene based material is yielded. Anyhow, the performance lags behind graphene prepared by other preparation methods if graphene oxide is processed at temperatures compatible with plastic substrates. State of the art performance is below $2000 \mathrm{~S} / \mathrm{cm}$ (conductivity of transparency). A thermal annealing step up to $1100{ }^{\circ} \mathrm{C}$ can increase the performance that is comparable to undoped graphene (about $4500 \mathrm{~S} / \mathrm{cm}$ ). Another approach, the dispersion of graphene obtained from graphite flakes can provide a conductivity of transparency up to about $3000 \mathrm{~S} / \mathrm{cm}$. Further, graphene or reduced graphene oxide were combined with other potential materials as carbon nanotubes and promising results up to $3 \times 10^{4} \mathrm{~S} / \mathrm{cm}$ are described. A lot of research was already done for doped carbon nanotubes and in dependence of their quality conductivities of transparency of $3 \times 10^{4}$ to $9 \times 10^{4} \mathrm{~S} / \mathrm{cm}$ are possible. The best quality to date was obtained by graphitization of molecular films, as oleic acid with a quality equal to films prepared by chemical vapour deposition. As a consequence doped graphene films with a conductivity of transparency of $2 \times 10^{5} \mathrm{~S} / \mathrm{cm}$ are possible, about three orders of magnitude better than for reduced graphene oxide. The quality is high enough to compete with commonly used indium tin oxide with a performance of $4 \times 10^{5} \mathrm{~S} / \mathrm{cm}$. But other materials are also promising, as single wall carbon nanotubes especially combined with thin gold film and silver nanowires are mentioned with 
$2-3 \times 10^{5} \mathrm{~S} / \mathrm{cm}$. Besides touch screen applications that will come to marked within the next few years, graphene can be used as transparent electrode for solar cells or thin film transistors. One must keep in mind the research on graphene just started and we will see which applications will become economically worthwhile but it is conceivable that graphene based technology will become an invisible part in our daily life.

\section{References}

Bae, S., et al. (2010). Roll-to-roll production of 30-inch graphene films for transparent electrodes, Nature Nanotechnology, 5, 8, pp. 574-578.

Becerril, H. A., et al. (2008). Evaluation of solution-processed reduced graphene oxide films as transparent conductors, ACS Nano, 2, 3, pp. 463-470.

Behabtu, N., et al. (2010). Spontaneous high-concentration dispersions and liquid crystals of graphene, Nature Nanotechnology, 5, 6, pp. 406-411.

Berger, C., et al. (2004). Ultrathin Epitaxial Graphite: 2D Electron Gas Properties and a Route toward Graphene-based Nanoelectronics, The Journal of Physical Chemistry B, 108, 52, pp. 19912-19916.

Blake, P., et al. (2008). Graphene-Based Liquid Crystal Device, Nano Letters, 8, 12, pp. 17041708.

Boehm, H. P., et al. (1962). Dünnste Kohlenstoff-Folien, Zeitschrift für Naturforschung, 17b, 150-153.

Brodie, B. C. (1855). Note sur un nouveau procédé pour la purification et la désagrégation du graphite, Ann. Chim. Phys., 45, pp. 351-353.

Casabianca, L. B., et al. (2010). NMR-Based Structural Modeling of Graphite Oxide Using Multidimensional ${ }^{13} \mathrm{C}$ Solid-State NMR and ab Initio Chemical Shift Calculations, Journal of the American Chemical Society, 132, 16, pp. 5672-5676.

Casiraghi, C., et al. (2007). Rayleigh imaging of graphene and graphene layers, Nano Letters, 7, 9, pp. 2711-2717.

Charpy, G. (1909). Lur sar formation de l'oxyde graphitique et la définition du graphite, Comptes rendus hebdomadaires des séances de l'Académie des sciences, 148, pp. 920-923.

Choi, D., et al. (2010). Fully Rollable Transparent Nanogenerators Based on Graphene Electrodes, Advanced Materials, 22, 19, pp. 2187-2192.

Choi, J.-Y., et al. (2009). Transparent electrode comprising graphene sheet, and display and solar cell including electrode, US2009071533.

Chung, D. D. L. (2002). Review Graphite, Journal of Materials Science, 37, 8, pp. 1475-1489.

Compton, O. C. \& S. T. Nguyen (2010). Graphene oxide, highly reduced graphene oxide, and graphene: versatile building blocks for carbon-based materials, Small, 6, 6, pp. 711-723.

Cote, L. J., et al. (2009). Langmuir-Blodgett Assembly of Graphite Oxide Single Layers, Journal of the American Chemical Society, 131, 3, pp. 1043-1049.

Cravotto, G. \& P. Cintas (2010). Sonication-Assisted Fabrication and Post-Synthetic Modifications of Graphene-Like Materials, Chemistry - A European Journal, 16, 18, pp. 5246-5259.

De, S., et al. (2009a). Silver Nanowire Networks as Flexible, Transparent, Conducting Films: Extremely High DC to Optical Conductivity Ratios, ACS Nano, 3, 7, pp. 1767-1774. 
De, S., et al. (2009b). Flexible, Transparent, Conducting Films of Randomly Stacked Graphene from Surfactant-Stabilized, Oxide-Free Graphene Dispersions, Small, 6, 3, pp. 458-464.

Debye, P. \& P. Scherrer (1917). Über die Konstitution von Graphit und amorpher Kohle, Nachrichten von der Gesellschaft der Wissenschaften zu Göttingen, MathematischPhysikalische Klasse, 1917, 2, pp. 180-188.

Dimroth, O. \& B. Kerkovius (1913). Zur Kenntnis der Konstitution der Kohle, Justus Liebigs Annalen der Chemie, 399, 1, pp. 120-123.

Eda, G. \& M. Chhowalla (2010). Chemically Derived Graphene Oxide: Towards Large-Area Thin-Film Electronics and Optoelectronics, Advanced Materials, 22, 22, pp. 23922415.

Eda, G., et al. (2008a). Large-area ultrathin films of reduced graphene oxide as a transparent and flexible electronic material, Nature Nanotechnology, 3, 5, pp. 270-274.

Eda, G., et al. (2008b). Transparent and conducting electrodes for organic electronics from reduced graphene oxide, Applied Physics Letters, 92, pp. 233305.

Eigler, S. (2009). A new parameter based on graphene for characterizing transparent, conductive materials, Carbon, 47, 12, pp. 2936-2939.

Feng, C., et al. (2010). Flexible, Stretchable, Transparent Conducting Films Made from Superaligned Carbon Nanotubes, Advanced Functional Materials, 20, 6, pp. 885-891.

Fraser, D. B. \& H. D. Cook (1972). Highly Conductive, Transparent Films of Sputtered $\mathrm{In}_{2-}$ ${ }_{x} \mathrm{Sn}_{\mathrm{x}} \mathrm{O}_{3-\mathrm{y}}$, Journal of the Electrochemical Society, 119, 10, pp. 1368-1374.

Gan, Y., et al. (2003). STM investigation on interaction between superstructure and grain boundary in graphite, Surface Science, 539, 1-3, pp. 120-128.

Geng, J. \& H.-T. Jung (2010). Porphyrin Functionalized Graphene Sheets in Aqueous Suspensions: From the Preparation of Graphene Sheets to Highly Conductive Graphene Films, Journal of Physical Chemistry C, 114, 18, pp. 8227-8234.

Gómez-Navarro, C., et al. (2010). Atomic Structure of Reduced Graphene Oxide, Nano Letters, 10, 4, pp. 1144-1148.

Gottschalk, F. (1865). Beiträge zur Kenntniss der Graphitsäure, Journal für Praktische Chemie, 95, 1, pp. 321-350.

Hamdi, H. (1942). Zur Kenntnis der kolloidchemischen Eigenschaften des Humus Dispersoidchemische Beobachtungen an Graphitoxyd, Kolloid-Beihefte, 54, 10-12, pp. 554-634.

Hernandez, Y., et al. (2008). High-yield production of graphene by liquid-phase exfoliation of graphite, Nature Nanotechnology, 3, 9, pp. 563-568.

Hirata, M., et al. (2004). Thin-film particles of graphite oxide 1: High-yield synthesis and flexibility of the particles, Carbon, 42, 14, pp. 2929-2937.

Hong, T.-K., et al. (2010). Transparent, Flexible Conducting Hybrid Multilayer Thin Films of Multiwalled Carbon Nanotubes with Graphene Nanosheets, ACS Nano, 4, 7, pp. 3861-3868.

Hummers, W. S. (1957). Pereparation of graphitic acid, US2798878.

Juang, Z.-Y., et al. (2010). Graphene synthesis by chemical vapor deposition and transfer by a roll-to-roll process, Carbon, 48, 11, pp. 3169-3174. 
Kim, K. S., et al. (2009). Large-scale pattern growth of graphene films for stretchable transparent electrodes, Nature, 457, 7230, pp. 706-710.

King, P. J., et al. (2010). Improvement of Transparent Conducting Nanotube Films by Addition of Small Quantities of Graphene, ACS Nano, 4, 7, pp. 4238-4246.

Kovtyukhova, N. I., et al. (1999). Layer-by-Layer Assembly of Ultrathin Composite Films from Micron-Sized Graphite Oxide Sheets and Polycations, Chemistry of Materials, 11, 3, pp. 771-778.

Lee, J. H., et al. (2010). The Superior Dispersion of Easily Soluble Graphite, Small, 6, 1, pp. 58-62.

Lee, J. Y., et al. (2008). Solution-processed metal nanowire mesh transparent electrodes, Nano Letters, 8, 2, pp. 689-692.

Lerf, A., et al. (1998). Structure of Graphite Oxide Revisited, Journal of Physical Chemistry B, 102, 23, pp. 4477-4482.

Li, D., et al. (2008a). Processable aqueous dispersions of graphene nanosheets, Nature Nanotechnology, 3, 2, pp. 101-105.

Li, X., et al. (2008b). Highly conducting graphene sheets and Langmuir-Blodgett films, Nature Nanotechnology, 3, 9, pp. 538-542.

Li, X., et al. (2009). Transfer of Large-Area Graphene Films for High-Performance Transparent Conductive Electrodes, Nano Letters, 9, 12, pp. 4359-4363.

Loh, K. P., et al. (2010). The chemistry of graphene, Journal of Materials Chemistry, 20, 12, pp. 2277-2289.

Lu, X., et al. (1999). Tailoring graphite with the goal of achieving single sheets, Nanotechnology, 10, 3, pp. 269-272.

Marchand, R. F. (1845). Ueber die Einwirkung des Schwefelsäure auf die Holzkohle, Journal für Praktische Chemie, 35, 1, pp. 228-231.

Mattevi, C., et al. (2009). Evolution of Electrical, Chemical, and Structural Properties of Transparent and Conducting Chemically Derived Graphene Thin Films, Advanced Functional Materials, 19, 16, pp. 2577-2583.

Novoselov, K. S., et al. (2004). Electric Field Effect in Atomically Thin Carbon Films, Science, 306, 5696, pp. 666-669.

Park, H., et al. (2010a). Sonochemical hybridization of carbon nanotubes with gold nanoparticles for the production of flexible transparent conducing films, Carbon, 48, 5, pp. 1325-1330.

Park, H. J., et al. (2010b). Growth and properties of few-layer graphene prepared by chemical vapor deposition, Carbon, 48, 4, pp. 1088-1094.

Pham, V. H., et al. (2010). Fast and simple fabrication of large-scale transparent chemical converted graphene film by spraying deposition, Carbon, 48, 7, pp. 1945-1991.

Roddaro, S., et al. (2007). The optical visibility of graphene: interference colors of ultrathin graphite on $\mathrm{SiO}_{2}$, Nano Letters, 7, 9, pp. 2707-2710.

Rogers, R. E. \& W. B. Rogers (1850). Oxydation von Graphit und Diamant auf nassem Wege, Journal für Praktische Chemie, 50, 1, pp. 411-413.

Ruess, G. (1947). Über das Graphitoxyhydroxyd (Graphitoxyd), Monatshefte für Chemie, 76, 35, pp. 381-417. 
Ruess, G. \& F. Vogt (1948). Höchstlamellarer Kohlenstoff aus Graphitoxyhydroxyd, Kolloid Zeitschrift, 78, 3-4, pp. 222-242.

Schafhaeutl, C. (1840). Ueber die Verbindungen des Kohlenstoffes mit Silicium, Eisen und andern Metallen, welche die verschiedenen Gattungen von Gusseisen, Stahl und Schmiedeeisen bilden., Journal für Praktische Chemie, 21, 1, pp. 129-157.

Shin, H.-J., et al. (2009a). Reduced graphene oxide doped with dopant, thin layer and transparent electrode, US20090146111.

Shin, H.-J., et al. (2009b). Efficient Reduction of Graphite Oxide by Sodium Borohydride and Its Effect on Electrical Conductance, Advanced Functional Materials, 19, 12, pp. 19871992.

Soldano, C., et al. (2010). Production, properties and potential of graphene, Carbon, 48, 8, pp. 2127-2150.

Spath, T. M., et al. (2006). Touchscreen with conductive layer comprising carbon nanotubes, WO2008013517.

Staudenmaier, L. (1898). Verfahren zur Darstellung der Graphitsäure, Berichte der deutschen chemischen Gesellschaft, 31, 2, pp. 1481-1487.

Staudenmaier, L. (1899). Verfahren zur Darstellung der Graphitsäure, Berichte der deutschen chemischen Gesellschaft, 32, 2, pp. 1394-1399.

$\mathrm{Su}$, Q., et al. (2009). Composites of Graphene with Large Aromatic Molecules, Advanced Materials, 21, 31, pp. 3191-3195.

Thiele, H. (1937). Über Salzbildung und Basenaustausch der Graphitsäure, Kolloid Zeitschrift, 80,1, pp. 1-20.

Topsoe, H. (1968). Geometric factors in four point resistivity measurement, http://www.four-point-probes.com/haldor.html.

Tung, V. C., et al. (2009). Low-Temperature Solution Processing of Graphene-Carbon Nanotube Hybrid Materials for High-Performance Transparent Conductors, Nano Letters, 9, 5, pp. 1949-1955.

Vallés, C., et al. (2008). Solutions of Negatively Charged Graphene Sheets and Ribbons, Journal of the American Chemical Society, 130, 47, pp. 15802-15804.

Wang, S. J., et al. (2010). Fabrication of highly conducting and transparent graphene films, Carbon, 48, 6, pp. 1815-1823.

Wang, X., et al. (2008a). Transparent, conductive graphene electrodes for dye-sensitized solar cells, Nano Letters, 8, 1, pp. 323-327.

Wang, X., et al. (2008b). Transparent Carbon Films as Electrodes in Organic Solar Cells, Angewandte Chemie International Edition, 47, 16, pp. 2990-2992.

$\mathrm{Wu}$, J., et al. (2010). Organic Light-Emitting Diodes on Solution-Processed Graphene Transparent Electrodes, ACS Nano, 4, 1, pp. 43-48.

Wu, Z., et al. (2004). Transparent, Conductive Carbon Nanotube Films, Science, 305, 5688, pp. 1273-1276.

Xu, Y., et al. (2010). Polymer photovoltaic devices with transparent graphene electrodes produced by spin-casting, Carbon, 48, 11, pp. 3308-3311.

Yan, H., et al. (2009). Highly Conductive and Transparent Poly (3,4-ethylenedioxythiophene)/Poly(4-styrenesulfonate) (PEDOT/PSS) Thin Films, Polymer Journal, 41, 12, pp. 1028-1029. 
Zhang, B., et al. (2010). Stable dispersions of reduced graphene oxide in ionic liquids, Journal of Materials Chemistry, 20, 26, pp. 5401-5403.

Zhang, D., et al. (2006). Transparent, conductive, and flexible carbon nanotube films and their application in organic light-emitting diodes, Nano Letters, 6, 9, pp. 1880-1886.

$\mathrm{Zhu}, \mathrm{Y}$. , et al. (2009). Transparent self-assembled films of reduced graphene oxide platelets, Applied Physics Letters, 95, 10, pp. 103104. 


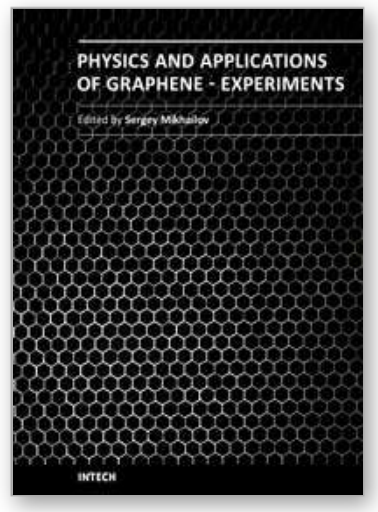

\author{
Physics and Applications of Graphene - Experiments \\ Edited by Dr. Sergey Mikhailov
}

ISBN 978-953-307-217-3

Hard cover, 540 pages

Publisher InTech

Published online 19, April, 2011

Published in print edition April, 2011

The Stone Age, the Bronze Age, the Iron Age... Every global epoch in the history of the mankind is characterized by materials used in it. In 2004 a new era in material science was opened: the era of graphene or, more generally, of two-dimensional materials. Graphene is the strongest and the most stretchable known material, it has the record thermal conductivity and the very high mobility of charge carriers. It demonstrates many interesting fundamental physical effects and promises a lot of applications, among which are conductive ink, terahertz transistors, ultrafast photodetectors and bendable touch screens. In 2010 Andre Geim and Konstantin Novoselov were awarded the Nobel Prize in Physics "for groundbreaking experiments regarding the two-dimensional material graphene". The two volumes Physics and Applications of Graphene - Experiments and Physics and Applications of Graphene - Theory contain a collection of research articles reporting on different aspects of experimental and theoretical studies of this new material.

\title{
How to reference
}

In order to correctly reference this scholarly work, feel free to copy and paste the following:

Siegfried Eigler (2011). Transparent and Electrically Conductive Films from Chemically Derived Graphene, Physics and Applications of Graphene - Experiments, Dr. Sergey Mikhailov (Ed.), ISBN: 978-953-307-217-3, InTech, Available from: http://www.intechopen.com/books/physics-and-applications-of-grapheneexperiments/transparent-and-electrically-conductive-films-from-chemically-derived-graphene

\section{INTECH}

open science | open minds

\section{InTech Europe}

University Campus STeP Ri

Slavka Krautzeka 83/A

51000 Rijeka, Croatia

Phone: +385 (51) 770447

Fax: +385 (51) 686166

www.intechopen.com

\section{InTech China}

Unit 405, Office Block, Hotel Equatorial Shanghai

No.65, Yan An Road (West), Shanghai, 200040, China

中国上海市延安西路65号上海国际贵都大饭店办公楼 405 单元

Phone: +86-21-62489820

Fax: $+86-21-62489821$ 
(C) 2011 The Author(s). Licensee IntechOpen. This chapter is distributed under the terms of the Creative Commons Attribution-NonCommercialShareAlike-3.0 License, which permits use, distribution and reproduction for non-commercial purposes, provided the original is properly cited and derivative works building on this content are distributed under the same license. 